\title{
THE EFFECT OF INTER-OCULAR DELAY AND REPETITION INTERVAL ON DEPTH PERCEPTION ${ }^{1}$
}

\author{
Eugene R. WIST ${ }^{2}$ and Walter C. Gogel \\ U.S. Army Medical Research Laboratory, Fort Knox, Kentucky, \\ and Psychology Department, University of California, Santa Barbara, California
}

(Received 8 June 1965)

\section{INTRODUCTION}

THE PROBLEM with which this study is concerned is the relationship between binocular fusion and simultaneity of stimulation of the two eyes. This relationship has considerable theoretical importance. For example, it is typically assumed that simultaneity of arrival of discharges at the cortex from the two retinas is a necessary condition for stereopsis. Also, this assumption of simultaneity is basic to the explanation of the Pulfrich effect (PULFRICH, 1922; LIT, 1949).

Evidence supporting the validity of the assumption of simultaneity is quite scanty (OGLE, 1954a, 1954b). It is certainly true that simultaneous stimulation of the two eyes is a sufficient condition for stereopsis, since under normal viewing conditions, discharges in the optic nerves of each eye resulting from binocular stimulation are present at the cortex simultaneously for fusion. The necessary conditions involved in the cortical interaction of stereoscopic inputs from the two eyes is not as clear cut, however, when certain novel viewing conditions are considered, for example, when the two eyes are stimulated successively rather than simultaneously or, as exemplified by the Pulfrich effect, when the stimuli in the two eyes are of different intensity. Under these latter conditions, discharges from the two eyes may arrive at the cortex at different times. Discharges arriving at the cortex at different times may nonetheless be simultaneously present for fusion as a result of long stimulus duration resulting in temporal overlap, or as a result of the persistence of cortical traces. If the temporal interval separating the cortical arrival of these discharges is great enough, no temporal overlap and hence no simultaneous presence either of the discharges themselves or of their traces will occur. Thus, the interocular temporal delay between brief stimuli as well as the duration of these stimuli and the duration of their cortical traces may determine the nature of the resulting interaction.

Stated more succinctly then, the assumption of simultaneity is the assumption that either contiguous cortical arrival or contiguous cortical presence (or both) of discharges or traces is a necessary condition for the occurrence of stereopsis. From studies of the relationship between the latency of cortical evoked potentials and light intensity (MONNIER, 1953; DONCHIN, WiCKE and LiNDSLEY, 1963), it follows that when the two eyes are stimulated simultaneously by photic stimuli of different intensity, a temporal difference occurs in the

\footnotetext{
${ }^{1}$ Portions of this paper were read at the Renshaw Vision Conference, Ohio State University, April 1963, and at the Psychonomics Society Meetings, Bryn Mawr College, August 1963.

2 Present address: Psychology Department, Franklin and Marshall College, Lancaster, Pennsylvania.
} 
time of arrival at the cortex of the resulting optic nerve discharges with this temporal difference proportional to the intensity difference. It also follows that if the two eyes are stimulated by flashes of equal intensity, differences in time of arrival at the cortex could be manipulated by varying the time of "departure" of a flash at each eye. That is, the delay introduced between the times of onset of the two equal-intensity flashes would result in a delay in time of arrival at the cortex equal to the difference in onset times. One implication of this reasoning is that interocular stimulus differences (differences between the two eyes) of either intensity or time can be used interchangably to produce differences in the time of arrival of discharges at the cortex.

It should be noted that regardless of the factors determining the cortical fusion of binocular impulses, as the interocular delay (IOD) between short duration stimuli increases, a delay value will be reached beyond which fusion of the two stimuli will be impossible. At this point an observer would see two flashes in succession each of which is perceived monocularly. Thus, varying the IOD interval will produce a continuum, one end of which is complete cortical fusion and stereopsis, the other end of which is no fusion and successive monocular observation of the flashes. The literal application of the assumption of simultaneity requires that a discontinuity occur between stereoscopic and monocular vision such that a very sharp change in stereopsis would occur at that IOD interval at which discharges or traces are not present simultaneously at the cortex. It was the purpose of the present study to investigate the stereoscopic consequences of temporal interocular differences in stimulation. For this purpose two variables, IOD interval and repetition interval (the time interval separating successive pairs of delayed flashes) were manipulated and their effect on depth location and stereoscopic acuity determined. The general procedure employed involved setting up an experimental situation in which a test object would be located by an observer at one depth position when binocularly fused and at a different depth position when no binocular fusion occurred, that is, when the stimulation was effectively monocular.

\section{METHOD}

Changes in stereoscopic effectiveness as a consequence of different temporal conditions was measured by having $O$ s stereoscopically place one object at the apparent depth of another. Two kinds of measures, mean localization and stereoscopic acuity were used as criteria. As will be discussed, the experimental situation was such that the adjustable object should have appeared at a different depth position when monocularly rather than binocularly viewed. Thus, a shift in mean localization in the proper direction or a decrease in stereoscopic acuity would indicate a decrease in stereoscopic effectiveness.

\section{Observers}

Three men and one woman were used as $O$ s unless otherwise indicated. All had an acuity of $20 / 20$ or better in each eye. Spectacles were worn by three of the four $O$ s. Their stereoacuities in seconds of arc were 115, 80, 39, and 39. Each $O$ was skilled at making stereoscopic judgments.

\section{Apparatus}

A Kepco Model 615 B d.c.-regulated power supply was coupled with a timing and flash generator (Roush and HA MBURGER, 1948) to drive two Sylvania, R1131C glow-modulator tubes fitted anterior to the reticle holders of a stereoptometer, a stereoscopic range finder of unit base and unit magnification (HARKER, 1955). A Tektronix Type 535, dual trace 
oscilloscope was used to measure the duration and temporal spacing of flashes produced by the flash generator. Each flash tube transilluminated a circular reticle consisting of a $0.45 \mathrm{~mm}$ aperture in an otherwise opaque photographic negative. The image of this aperture was collimated (placed at optical infinity) by the optical system of the stereoptometer.

Thus, an image of a luminous disc, requiring no accommodation, was presented to each eye. The stereoptometer also included a mechanical system which made possible a symmetrical change in the vergence of the eyes required to bring the reticle image on the fovea. Changing the vergence of the stereoptometer by turning an instrument dial resulted stereoscopically in the perception that the fused disc reticle image moved back or forth in depth.

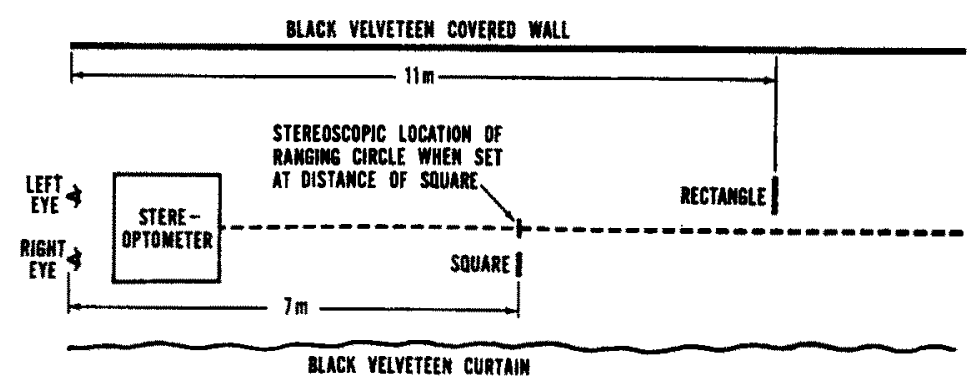

Fig. 1.

Figure 1 shows the perceived position of the fused disc reticle (hereafter referred to as the disc). A transilluminated square (located slightly to the right) was $7 \mathrm{~m}$ away from $O \mathrm{~s}^{\prime}$ ' eyes, and a transilluminated rectangle (located slightly to the left) was $11 \mathrm{~m}$ from $O \mathrm{~s}^{\prime}$ eyes. The remainder of the room was in darkness. A combination of light baffles, black velveteen drapes and a velveteen-covered floor insured that only these three stimuli were visible to $O$. The luminance of all three stimuli was $1.5 \mathrm{ft} \mathrm{L}$.

Figure 2 is a frontal view of the visual angles between the rectangle, disc, and square as well as their visual angular sizes. The rectangle and the square were always simultaneously, binocularly viewed.

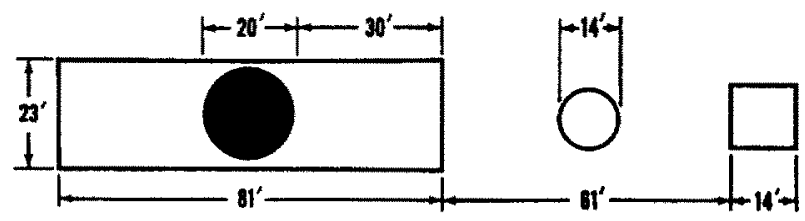

FIG. 2.

\section{Experimental design}

Light flashes of short duration were produced with the flash generator by exciting the glow modulator tubes with a voltage of rectangular waveform. The flash possessed a very rapid rise time and decay (approximately $30 \mu \mathrm{sec}$ ). Pairs of flashes $4 \mathrm{msec}$ in duration were generated, the first of which produced the dise of light in the left eye, the second of which after a specified delay interval produced the disc of light in the right eye. The delay interval between these flashes (IOD) was either 1, 2, 4, 8, 16, 32, 64, or 96 msec. The time between 
successive pairs of flashes (repetition interval) was either $150,300,600$, or $1200 \mathrm{msec}$ measured from the onset of the first member of the pair. Each IOD occurred in combination with each repetition interval for a total of 32 conditions.

A brightness matching procedure was used to equate the intensity of flashes in each eye. At the beginning of a session the disc was projected monoculariy so that it obscured the black disc in the center of the large rectangle (see Fig. 2). $O$ then adjusted the intensity of the flashing disc ( $4 \mathrm{msec}$ duration) so that it matched that of the rectangle $(1.5 \mathrm{ft} \mathrm{L})$. Ten matches were made with each eye and at repetition intervals of 150 and $600 \mathrm{msec}$. The mean of these matches was employed during the rest of the session. A pilot study indicated that matches made at 300,600 , and $1200 \mathrm{msec}$ did not differ significantly, although matches made at these repetition intervals all differed from those made at $150 \mathrm{msec}$.

Each $O$ experienced all 32 conditions, 8 per session, for 4 sessions. During each session an $O$ randomly received all 8 interocular delays at one of the four repetition intervals with the restriction that, for a given session, each $O$ received a different repetition interval. Within sessions the order of interocular delays was also randomly presented with the restriction that the longest delay did not occur first.

\section{The stereoscopic measure}

$O$ looked into the eye pieces of the stereoptometer and binocularly fused the disc presented to each eye. His task under each condition was to move the disc in depth until it appeared to be at the same distance as the square. Five consecutive adjustments were made for each condition. $O$ adjusted the disc to both the apparent distance of the rectangle and the square under conditions of $0 \mathrm{msec}$ IOD at both the beginning and end of each session in order to determine whether any criterion shift had taken place during the session.

\section{Light adaptation}

At the beginning of each session, $O$ received $10 \mathrm{~min}$ of light adaptation to a homogenous $1.5 \mathrm{ft} \mathrm{L}$ screen, 50 degrees high and 80 degrees wide. Adaptation also occurred after each block of five adjustments of the disc with the length of the adaptation period being either the time required for the five adjustments or $3 \mathrm{~min}$, whichever was shorter. These interspersed adaptation periods maintained a relatively constant state of light adaptation during the course of a session. Each session was approximately $75 \mathrm{~min}$ in duration with a 10 min rest after one-half of the adjustments were completed.

\section{RESULTS}

The raw data of the experiment consisted of the dial readings recorded from the stereoptometer. For each session, the mean disc setting to the apparent distance of the square under conditions of $0 \mathrm{msec}$ IOD was used as a baseline. This mean value was subtracted from each of the means for the five values obtained under the eight other IOD conditions to produce a measure of change in the stereoscopic location of the disc. The dial settings were transformed to convergence values expressed in seconds of arc by using the calibration constant of the instrument. The standard deviation of 5 consecutive adjustments by an $O$ under a particular condition was taken as the stereoacuity score for that $O$ for that condition. 


\section{The effect of interocular delay interval}

The solid line in Fig. 3 indicates the amount of shift in the depth position of the fused disc as a function of the IOD interval. Increasing values on the ordinate indicate a movement of the disc away from $O$. This figure shows that there was a negligible shift in depth of the disc between 1 and $32 \mathrm{msec}$ and a sizable shift between 32 and $96 \mathrm{msec}$. The dashed line shows the change in the standard deviation of the depth adjustments of the disc as a function

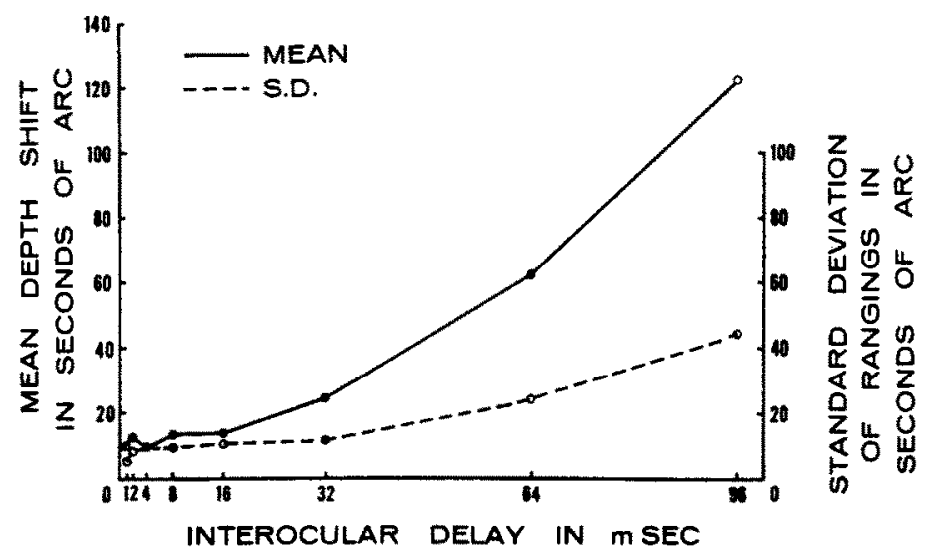

FIG. 3.

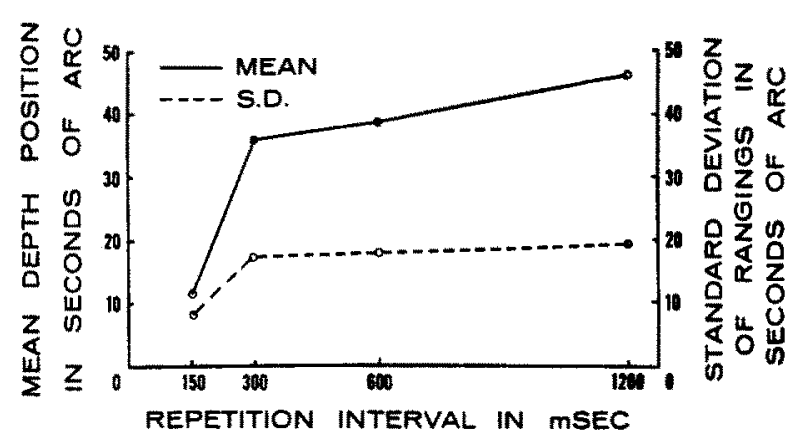

FIG. 4.

of IOD interval. The relationship is similar to that for the mean shift in position and indicates that virtually no shift in stereoacuity occurred until the IOD interval exceeded $32 \mathrm{msec}$. IOD had no apparent affect on stereoacuity from 1 to $32 \mathrm{msec}$. It should be noted that the data from the 300,600 , and $1200 \mathrm{msec}$ repetition intervals are combined in this graph. The data from the $150 \mathrm{msec}$ repetition interval were omitted because the effect of IOD was very different for this repetition interval.

The solid line in Fig. 4 shows the effect of repetition rate on the mean apparent distance of the disc. It is readily seen that the effect is asymptotic after a repetition interval of 300 msec. The dashed line indicates that the effect of repetition interval on stereoacuity was similar to the effect on mean position. Data from all eight IOD intervals were pooled in this figure. 
The interaction of interocular delay interval and repetition interval

The effect of repetition interval on the adjusted depth position of the disc for each of the eight IOD intervals can be seen in Fig. 5. The effect of repetition interval increased with increased IOD. The convergence of the curves in this figure on the 150 msec repetition interval means that, at this short interval, IOD had no apparent effect on the perceived position of the disc.

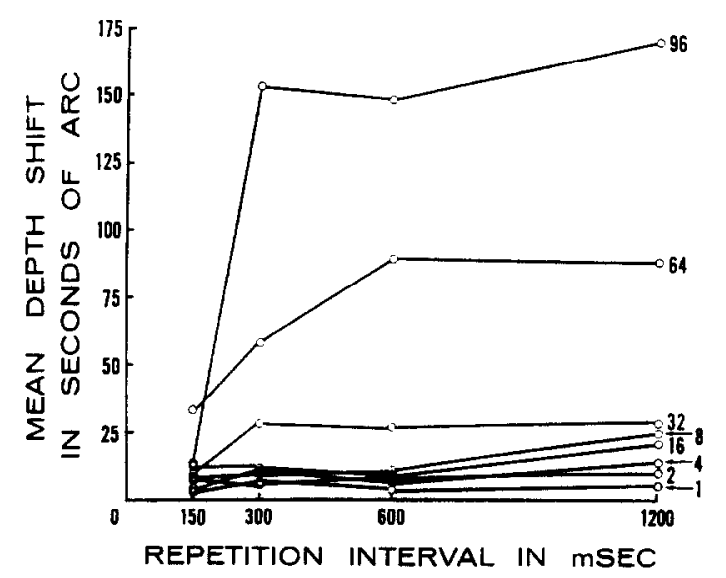

Fig. 5.

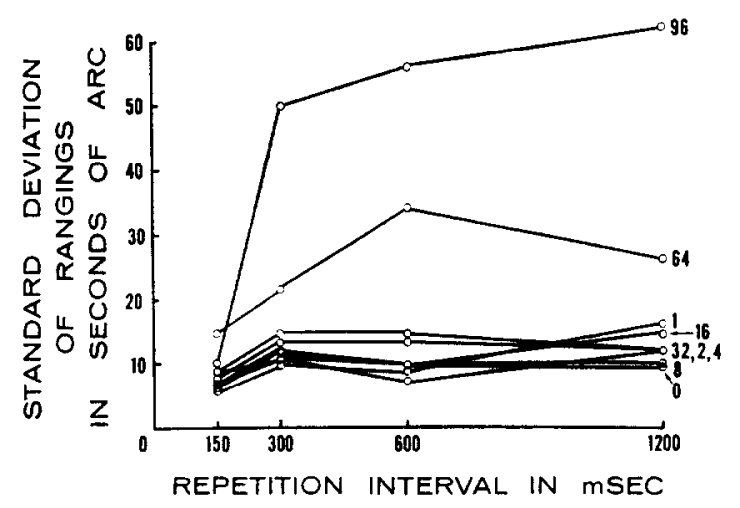

Fig. 6.

Figure 6 is very similar in form to Fig. 5 but indicates the effect of repetition interval and IOD interval on stereoacuity rather than depth location, as measured by the standard deviation of disc adjustments. The major difference between this figure and Fig. 5 is that "spread" of the curves is more restricted between IODs of 0 and $32 \mathrm{msec}$ than in the former figure.

\section{DISCUSSION}

At least four important findings are evident in the data of this study: (1) Little or no change in either depth location or stereoacuity occurred with IODs of $32 \mathrm{msec}$ or less. (2) With larger IODs, the apparent position of the disc shifted away from $O$ and stereoacuity 
decreased. (3) Increasing the repetition interval from 150 to $300 \mathrm{msec}$ resulted in a shift in the apparent position of the disc away from $O$ and decreased stereoacuity. (4) There was an interaction between repetition interval and IOD such that repetition interval had a larger effect for longer IOD intervals.

These findings support the notion of a continuum between stereoscopic-binocular and monocular stimulation. No sharp discontinuity was observed in the data. Physical simultaneity was not a necessary condition for stereopsis. The position of the disc remained relatively constant until the IOD interval exceeded $32 \mathrm{msec}$ at which point its position shifted gradually away from $O$. This shift is indicated by the need to adjust the disc closer to the $O$ in order for it to appear equidistant with the square.

The apparent recession in depth of the disc with increasing IOD might be explained by assuming that as the IOD interval increased the disc became "more monocular" (or "less binocular") and therefore more subject to the operation of the equidistance tendency. According to the equidistance tendency, the disc, if observed monocularly, should appear approximately midway in depth between the binocularly observed square and rectangle (GOGEL, 1956). That the equidistance tendency could be effective here was verified for each $O$ by turning off the disc stimulus to the left eye and obtaining a verbal report of the apparent depth position of the disc. Under these conditions the average report was that the disc was $5 \mathrm{ft}$ behind the square and $4 \mathrm{ft}$ in front of the rectangle. It would therefore be expected that as the disc became effectively more monocular with, for example, increased IOD, the disc should appear behind the square and that stereoscopically the disc would have to be moved increasing amounts in front of the square in order to appear equidistant with the square.

In order to verify this explanation the rectangle was switched off for several $O$ s before a block of trials. If the rectangle were responsible for the receding of the disc, then its absence should result in no shift in the depth location of the disc as a function of IOD. It was found, however, that the disc still receded even though the rectangle was not present, although the amount of recession was somewhat less than in the rectangle's presence and stereoacuity was poorer. The similarity in size of the disc and the square permits the hypothesis that perhaps Panum's Limiting Case was the basis of the depth shift in the absence of the rectangle. According to Panum's Limiting Case, when two similar objects, not too far separated in direction are simultaneously viewed, one binocularly and one monocularly, the objects will appear to be at different distances (OGLE, 1962). In the classical example, a stereogram containing one vertical line in, say, the left eye view, and two parallel vertical lines less than a degree apart in the right eye view is fused binocularly. The line in the left eye view fuses with either of the two lines in the right eye view (depending on the amount of convergence of the two eyes). Regardless of which pair is fused, the result is that the monocular line (the one not fused) is perceived as being at a different distance than the binocular (fused) line. In the present experiment, it is possible that with increased IOD, the disc image in the left eye (since it was presented first) satisfied the conditions of Panum's Limiting Case, with the result that the disc shifted away from $O$ in apparent depth. Removal of the rectangle did not affect the conditions of Panum's Limiting Case and therefore did not prevent the disc from receding. The fact that the disc receded more when the rectangle was present rather than absent suggests that the effect of Panum's Limiting Case and the equidistance tendency summate in this experiment.

A subsequent unpublished study has shown that when the equidistance object is placed between $O$ and the square, the magnitude of the depth shift of the disc as a function of IOD interval could be attenuated. $O$ viewed the disc through a horizontal aperture in a large 
transilluminated binocular screen. The square was located behind and adjacent to the screen. When viewed monocularly, the disc appeared at the distance of the screen rather than the square in accordance with the equidistance tendency, since the lateral separation between it and the screen was less than between it and the square. When only the disc (viewed with the left eye only) and the square viewed binocularly were present, the disc appeared behind the square in accordance with Panum's Limiting Case. Thus, in this situation, the equidistance tendency and Panum's Limiting Case are in opposition, with the former "pulling" the disc forward and the latter "pulling" it back. It should be pointed out that the effects of the equidistance tendency and of Panum's Limiting Case are dependent on the IOD interval. As long as this interval is short, the binocular disparity cue overrides their influence. As the IOD interval increases, the binocular disparity gradually shades into alternate monocular vision thus allowing the equidistance tendency or possibly Panum's Limiting Case (or both) to determine depth location.

Alternate hypotheses concerning the basis of the observed phenomena are possible. It is possible that a change in the position of the eyes relative to each other during the IOD interval resulted in a change in the depth location of the disc by increasing the retinal disparity between the disc and the square. In order for this to occur, the eyes would have to converge during the IOD interval by an angular amount equal to the depth shift, e.g. some $175 \mathrm{sec}$ arc for an IOD of $96 \mathrm{msec}$ at a repetition interval of $1200 \mathrm{msec}$. A subsequent, unpublished experiment in which the convergence of the eyes and depth position of the disc were measured simultaneously demonstrated, however, that there was no relationship between eye movements during the IOD interval and depth or stereoacuity shifts.

Alternative hypotheses involving perceptual blanking (KOLERS and ROSNER, 1960: WAGMAN and BATTERSBY, 1957), contour development (SMITH and GULICK, 1962) and two-flash thresholds (MAHNEKE, 1958; IRELAND, 1964) are currently being tested.

There appears to be only one other study in the literature in which the effects of IOD on stereoscopic depth has been investigated with a binocular, continuously visible fixation point to provide stable fusion (OGLE, 1963). There are three others (RICHARDS, 1951; EFron, 1957; and DoDwELL and ENGEL, 1963) in which alternate viewing of the two halves of a stereogram occurred. Consequently, in these latter studies, no stable fixation point was available for the maintenance of fusion.

The results of the present study are in good agreement with those of the OGLE (1963) study in spite of differences in procedure. Using a white thread plumb line at $40 \mathrm{~cm}$ from $O$ as a standard and a fixation point, Ogle presented the variable stimulus (haploscopically fused line-filaments of incandescent bulbs) at various angular disparities and with various interocular delay intervals. Using the method of constant stimuli the threshold IOD interval which resulted in a shift in stereoscopic depth was determined for several stimulus durations. Although delays were produced by means of solenoid activated shutters resulting in a rise time of several milliseconds (as compared to $30 \mu \mathrm{sec}$ in the present experiment) the limits of stereoacuity as a function of IOD interval were quite similar to those of the present experiment. These limits ("critical delay times") were determined from the stereoacuity scores which were taken as the reciprocal of the standard deviation of the responses. The critical delay times ranged between a minimum of about $25 \mathrm{msec}$ for repetitive exposures of the flash pairs $50 \mathrm{msec}$ in duration to $160 \mathrm{msec}$ for a flash duration of $100 \mathrm{msec}$ single exposure. Critical delay times calculated from the data of the present experiment fall with this range.

In EFRON's experiment (1957) a delay interval between the presentations of the two halves of a stereogram was manipulated, as well as the stimulus duration and repetition 
interval. The latter variable was not independent of the interocular delay interval and stimulus duration, but as a result of the nature of the sectored discs employed for timing purposes, was inversely related to the former and directly related to the latter. The lack of a stable fixation point and temporal summation across repetition intervals tended to extend the IOD interval at which stereoscopic depth was reported (about $65 \mathrm{msec}$ at the shortest IOD and repetition intervals).

DODWELL and ENGEL (1963) have confirmed the findings of EFRON (1957) in a similar experiment and have offered a neurological model for binocular fusion. They reject with EFRON (1957), the possibility suggested by RICHARDS (1951) that some sort of central scanning process is possible in binocular fusion. If such were the case, one would expect to find certain presentation frequences at which fusion is maximal which depended on the frequency of the central scanning process. No such frequency was found in either the Dodwell and Engel or Efron studies or in the present study. The neural model they propose would predict that the depth shift would be toward rather than away from the observer as a function of IOD interval. The data of the present experiment do not support this prediction.

\section{REFERENCES}

Dodwell, P. C. and ENGer, G. R. (1963). A theory of binocular fusion. Nature 196, 39-40, 73-74.

DONChIN, E., WICKE, J. D. and LindSLEY, D. B. (1963). Cortical evoked potentials and perception of paired flashes. Science 141, 1285-1286.

EFRON, R. (1957). Stereoscopic Vision. I. Effect of binocular temporal summation. Br. J. Opthal. 41, 709-730.

GOGEL, W. C. (1956). The tendency to see objects as equidistant and its inverse relation to lateral separation. Psychol. Monogr. 70, Whole No. 411.

Gogel, W. C. (1963). The visual perception of size and distance. Vision Res. 3, 101-120.

HARKKER, G. S. (1955). Instrument for the study of binocular vision. J. opt. Soc. Am. 45, 826-828.

IRELAND, F. H. (1954). An experimental investigation of the monocular and binocular two pulse interval. Unpublished doctoral dissertation, Fordham University, New York.

Kolers, P. A. and RosNer, B. S. (1960). On visual masking (Metacontrast): Dichoptic observation. Am. J. Psychol. 73, 2-21.

LIT, A. (1949). The magnitude of the Pulfrich stereophenomenon as a function of binocular differences in intensity at various levels of illumination. Am. J. Psychol. 62, 159-181.

MAHNEKE, A. (1958). Foveal discrimination measured with two successive light fiashes. Acta ophthal. 36, 12-18.

MONNIER, M. (1953). Retinal, cortical and motor responses to photic stimulation in man. Retino-cortical time and opto-motor integration time. J. Neurophysiol. 15. 469-486.

OGLE, K. N. (1954a). Basis of stereoscopic vision. A.M.A. Arch. opthal. 52, 197-211.

OGLE, K. N. (1954b). On stereoscopic depth perception. J. exp. Psychol. 48, 225-233.

OGLE, K. N. (1962). The Optical Space Sense. In Visual Optics and the Optical Space Sense. Vol. 4. Davson, H. (Ed.). Academic Press, New York.

OGLE, K. N. (1963). Stereoscopic depth with delayed presentation of images in the two eyes. J. opt. Soc. Am. 53, 1296-1304.

Pulfrich, C. (1922). Die Stereoskopie im Dienste der isochromen and heterochromen Photometrie II. Anwendungen der neuen Methode. Naturwissenschaften 33, 714-722.

RICHARDS, W. (1951). The effect of alternating views of the test object on vernier and stereoscopic acuities. J. exp. Psychol. 42, 376-383.

Roush, R. and HAMBurger, F., Jr. (1948). Light-flash generator. Electronics 21, $100-102$.

SMITH, W. M. and Gulick, W. L. (1962). A statistical theory of dynamic contour perception. Psychol. Rev. 69, 91-108.

Wagman, I. and Battersey, W. (1959). Neural limitations of visual excitability: 11. Retrochiasmal interaction. Am. J. Physiol. 197, 1237-1242.

WERNER, H. (1940). Studies on contour: Strobostereoscopic phenomena. Am. J. Psychol. 53, 418-422. 
Abstract-Observers viewed a continuously illuminated, binocular standard stimulus, adjacent to which appeared a briefly illuminated, binocular comparison stimulus. Using the method of adjustment, observers positioned the comparison stimulus in depth so that it appeared equidistant to the standard stimulus under conditions in which an interocular delay in stimulation occurred with respect to the comparison stimulus. It was found that: (1) little change in equidistance settings occurred with delays of $32 \mathrm{msec}$ or less, but that with larger delays the apparent position of the comparison stimulus shifted away from the observer. (2) Increasing the time interval between successive pairs of comparison stimulus presentations from 150 to $300 \mathrm{msec}$ resulted in a similar shift in apparent position. (3) There was an interaction between delay and repetition interval such that the repetition interval had a larger effect on equidistance settings for longer delays. The results were interpreted as supporting the notion of a continuum between stereoscopic-binocular and monocular stimulation. Physical simultaneity was not a necessary condition for stereopsis.

Résumé-On présente à des observateurs un stimulus binoculaire standard éclairé en permanence, et un stimulus binoculaire de comparaison adjacent, qui n'apparaît illuminé que brièvement. Par la méthode d'ajustement les observateurs situent en profondeur le stimulus de comparaison afin qu'il paraisse à la mème distance que le stimulus standard lorsque on produit un délai interoculaire de stimulation dans le stimulus de comparaison. On trouve les résultats suivants: (1) avec des délais de $32 \mathrm{msec}$ ou moins, il y a peu de changement dans la profondeur tandis que pour des délais plus grands le stimulus de comparaison parait $s$ èloigner de l'observateur. (2) L'augmentation de l'intervalle de temps entre les paires successives du stimulus de comparaison, de 150 à $300 \mathrm{msec}$, produit un décalage analogue dans la position apparente. (3) Il y a une interaction entre le délai et l'intervalle de répétition telle que lintervalle de répétition a plus d'effet sur l'équidistance pour des délais plus longs. On interprète les résultats comme un argument en faveur de la notion de continuité entre la stimulation stéréoscopique binoculaire et monoculaire. La simultanéité physique n'est pas une condition nécessaire de stéréopsie.

Zusammenfassung-Den Versuchspersonen wurde ein binokularer Standard-Dauerreiz dargeboten, neben dem ein kurzzeitiger binokularer Vergleichsreiz erschien. Die Versuchspersonen stellten den Vergleichsreiz in der Tiefe so ein, dass er in der gleichen Entfernung wie der Standardreiz erschien. Dic Darbictung des Vergleichsreizes erfolgte mit einer interokularen Verzögerung. Es ergab sich: (1) Nur geringe Abweichungen von der äquidistanten Einstellung treten auf bei Verzögerungen von $32 \mathrm{msec}$ oder weniger, jedoch verschiebt sich mit grösseren Verzögerungen die scheinbare Lage des Vergleichsreizes in Richtung vom Beobachter weg. (2) Eine Vergrösserung des Zeitintervalls zwischen aufeinanderfolgenden Paaren von Vergleichsreizdarbietungen von 150 auf $300 \mathrm{msec}$ bewirkt eine ähnliche Verschiebung der scheinbaren Lage. (3) besteht eine Wechselwirkung zwischen der Verzögerung und dem Widerholungsintervall in der Art. dass das Wiederholungsintervall bei grösseren Verzögerungen einen grösseren Einfluss auf die äquidistante Einstellung hat. Die Ergebnisse werden als Unterstützung der Annahme eines Kontinuums zwischen der stereoskopischbinokularen und der monokularen Reizung interpretiert. Physikalische Gleichzeitigkeit ist keine notwendige Bedingung für stereoskopisches Sehen.

Резюме-Испытуемые наблюдали постоянно освешенный бинокулярный стандартный стимул, рядом с которым появлялся для сравнения освешаемый на короткое время бинокулярный стандартный стимул. Использован метод коррегирования испытуемыми положения сравниваемого стимула в глубину так, чтобы он казался на одинаковом расстоянии со стандартным стимулом, в таких условиях когда получалась задержка в стимуляшии для сравниваемого стимула. Найдено, что: (1) небольшие изменения неравенства расстояний получались при интервале в 32 мсек. и менее, но при большей задержке кажущееся положение стимула сравнения отодвигалось от наблюдателя; (2) увеличение временно́го интервала между сукцессивно предъявляемыми парами стимулов от 150 до 300 мсек. приводит к сходному смешению в кажушемся положении; (3) наблюдалось взаимодействие между степенью задержки и интервалом повторения такого рода, что при более длительной задержке интервал повторения стимулов имел большее влияние для помещения их на равных расстояниях. Результаты интерпретируются таким образом, что они поддерживают понятие непрерывности стереовосприятия при бинокулярной и монокулярной стимуляции. Одномоментность стимуляции обоих глаз-не является обязательным условием стереосиса. 